\title{
13
}

\section{Factors Affecting Scour of Previously Captured Sediment from Stormwater Catchbasin Sumps}

\author{
Humberto Avila, Robert Pitt and S. Rocky Durrans
}

The sediment-retaining performance in conventional catchbasin sumps has been reported to be in the wide range between 14 and 99\% (Metcalf \& Eddy 1977); obviously, the higher performance is obtained by combining low flowrates, large particle sizes, and high specific gravities. Typically, about $30 \%$ of the total stormwater particulates are captured in properly designed catchbasin sumps during actual rainfall tests (Pitt 1985). The accumulation rate, or sediment-retaining performance, depends on the size and geometry of the device, the flow rate, sediment size, and specific gravity of the sediment. In the same way, scour phenomenon includes all those parameters previously mentioned, in addition to the depth of the water protection layer above the sediment and the consolidation of the sediment bed due to aging after each runoff event.

A series of tests was conducted to evaluate the importance of the parameters and their interactions on the phenomenon of scour and the migration of sediment out of a conventional catchbasin sump located at a stormwater inlet. A 2-dimensional computational fluid dynamics model (CFD), using Fluent 6.2, was used to conduct a full factorial experimental design experiment that examined four parameters: flow rate, sediment size,

Avila, H., R.E. Pitt and S. Durrans. 2008. "Factors Affecting Scour of Previously Captured Sediment from Stormwater Catchbasin Sumps." Journal of Water Management Modeling R228-13. doi: 10.14796/JWMM.R228-13.

(C) CHI 2008 www.chijournal.org ISSN: 2292-6062 (Formerly in Reliable Modeling of Urban Water Systems. ISBN: 978-0-9808853-0-9) 
overlying water protection depth, and specific gravity of the sediment. The scour results were evaluated using predicted shear stress values for different depths in the catchbasin sump.

These modeling tests identified important differences in predicted shear stress values as a function of the flow rate, inlet geometry, and sediment elevation (overlying water depth). Flow rate and sediment size were the most important factors that explained sediment scour. The depth of the water over the sediment provided scour protection to the underlying material and was also identified as an important factor. However, specific gravity of the sediment material was not as important as the sediment particle size, or the water protection depth, on the prediction of sediment scour. Different inlet geometries also had a significant effect on the predicted scour conditions: inline catchbasins having circular pipe inlets have much greater predicted shear stress values compared to a rectangular inlet associated with gutter flows.

The predicted rates of shear stresses at different elevations in a catchbasin sump are consistent with the development of the predicted velocity fields. The protecting water layer above the sediment bed is more important for the smaller flow rates; higher flow rates can cause large shear rates even with deep water layers due to the circulation pattern that is developed with continuous flows.

These scour observations are similar to what has been observed during field tests of catchbasins in the past. The next stage of this research program will directly measure the 3-D velocity fields in the laboratory using a fullsized catchbasin with a sump to confirm these calculations, followed by selected controlled scour tests for further confirmation. Finally, the results will be implemented in the WinSLAMM stormwater model to better consider sediment scour from small hydrodynamic devices.

\subsection{Methodology}

Two different sets of modeling experiments were performed to evaluate the factors that affect scour of sediment from stormwater catchbasin sumps: (i) A $2^{4}$-full factorial experimental design to identify the most important factors and their interactions considering flow rate, sediment particle size, water depth, and specific gravity; and (ii) A response-surface examination of shear stress at different sediment elevations, caused by different flow rates and inlet geometries. Both experiments used Computational Fluid Dynamics (CFD) modeling using Fluent 6.2 (Fluent Inc., Lebanon, NH). 
Before the CFD modeling was conducted, a great deal of background work with the model was necessary to ensure reasonable results. CFD modeling is very sensitive to many modeling parameters and options. We based our initial model setup on prior CFD modeling of similar devices as reported in the literature, from discussions with many other CFD modelers, and on prior laboratory and field monitoring results of catchbasins. As an example, we found that the inlet geometry was very important, as a circular inlet concentrates the energy from the cascading water into a much smaller area than a rectangular inlet. Circular inlets are common for in-line proprietary devices, while rectangular inlets better represent gutter flows into catchbasin inlets, the main focus of our initial studies of scour.

\subsubsection{Experimental Design for Four Factors}

A $2^{4}$-full factorial experimental design (without replicates) (Box, et al. 1978) was used to determine the significance of four factors (flow rate, sediment particle size, water depth, and specific gravity), and their interactions, on the scour of previously captured sediment from of a catchbasin sump. The model was established as a continuous flow of a submersible-water jet (impact geometry determined after detailed evaluations of the cascading water from the inlet flows) during a 3,600 sec $(1 \mathrm{~h})$ period of time. There were obvious changes in the flow field and resulting shear stress values with time, so model results from several time periods were examined. Table 13.1 shows the factors with their corresponding low and high values that were used during the different experiments.

Table 13.1 Factors and Settings for the $2^{4}$-full factorial experimental design.

\begin{tabular}{llcc}
\hline & Factor & Low Values & High Values \\
\hline A & Flow rate $(\mathrm{L} / \mathrm{s})$ & 1.6 & 20.8 \\
B & Particle size $(\mu \mathrm{m})$ & 50 & 500 \\
C & Water Depth $(\mathrm{m})$ & 0.2 & 1.0 \\
$\mathrm{D}$ & Specific gravity & 1.5 & 2.5 \\
\hline
\end{tabular}

\subsubsection{Evaluation of Shear Stress}

The objective of additional response surface experiments was to calculate and compare the shear stresses caused by different combinations of flow rate, overlying water depth above the sediment, and inlet geometry, with 
critical shear stresses for different particle sizes having different specific gravities. Air entrainment was included in this case to consider the effect of water density variation and buoyancy in the impacting zone, which reduces the ability of the plunging water jet to reach the sediment layer and suspend it. However, this part of the analysis does not include sediment in the simulation, but only water and air. The scour potential of sediment is indirectly determined by calculating the maximum shear stress on a flat surface (assumed as sediment layer), and comparing it to the permissible shear stress for specific particle sizes.

Three different water depths above the sediment were evaluated: 1.0, 0.8, and $0.6 \mathrm{~m}$ below the outlet and above the sediment. During field monitoring, sediment usually accumulates until it has reached an elevation of about $0.3 \mathrm{~m}$ below the outlet (Pitt 1979 and 1985). Five different flow rates were considered: 2, 5, 10, 20, and $40 \mathrm{~L} / \mathrm{s}$ (32, 80, 160, 320, and $640 \mathrm{GPM})$; inflowing water was assumed to be relatively clear. These flow rates are within the range used by Metcalf \& Eddy (1977) in their laboratory studies, and also by the modeling studies conducted by Faram, et al. (2003) to evaluate the sediment removal and retention capabilities of stormwater treatment chambers. These flows are high when compared to typical inlet flows for catchbasin inlets, but were selected to correspond to the available earlier laboratory and CFD test results to enable suitable comparisons. Table 13.2 shows typical flow rate values (in gallons per minute) for an acre of pavement (a typical drainage area for a single inlet) for five different US cities for a single typical rain year.

Table 13.2 Annual Flow Rate Distributaries (GPM/acre pavement), (1 L/s $\approx 16$ GPM) (Pitt and Khambhammettu 2006).

\begin{tabular}{lcccc}
\hline Location & $\begin{array}{c}50^{\text {th }} \\
\text { Percentile }\end{array}$ & $\begin{array}{c}70^{\text {th }} \\
\text { Percentile }\end{array}$ & $\begin{array}{c}90^{\text {th }} \\
\text { Percentile }\end{array}$ & $\begin{array}{c}\text { Maximum flow rate expected } \\
\text { during typical rain year }\end{array}$ \\
\hline Seattle, WA & 16 & 28 & 44 & 60 \\
Portland, ME & 31 & 52 & 80 & 130 \\
Milwaukee, WI & 35 & 60 & 83 & 210 \\
Phoenix, AZ & 38 & 60 & 150 & 190 \\
Atlanta, GA & 45 & 65 & 160 & 440 \\
\hline
\end{tabular}

In the CFD model, the sediment surface was assumed to be a flat static wall, with a roughness of $1.0 \mathrm{~mm}$. However, the sediment bed is actually a loose boundary that will create bed-forms when the velocity field acts on it during long periods of time. Therefore, the criterion assumed to define the time 
limit of simulation is when the maximum shear stress affecting the top of the sediment layer reaches a maximum value with minimum variation. Different shear stress criteria, such as Shields (Vanoni, 1975), Van Rijn (1984), Cheng and Chiew (1999), and others, were reviewed during this research to identify a suitable set of critical shear stress criteria concerning the initial motion and initial suspension thresholds, as a function of sediment characteristics.

\subsection{Description of the Models}

The geometry of the manhole was the same as the optimal manhole geometry recommended by Larger, et al. (1977), and tested by Pitt 1979; 1985; and 1993. For this geometry, if the outlet diameter is D, the total height of the manhole is $6.5 \mathrm{D}$ and the inside diameter is $4 \mathrm{D}$; the outlet has to be located 4D above the bottom and 2.5D below the top of the manhole. The outlet diameter (D) was selected as $300 \mathrm{~mm}$. A 2-dimensional model (2D) was implemented in Fluent 6.2 by using the longitudinal center-line cross section on the predominant flow direction (see Figure 13.1).
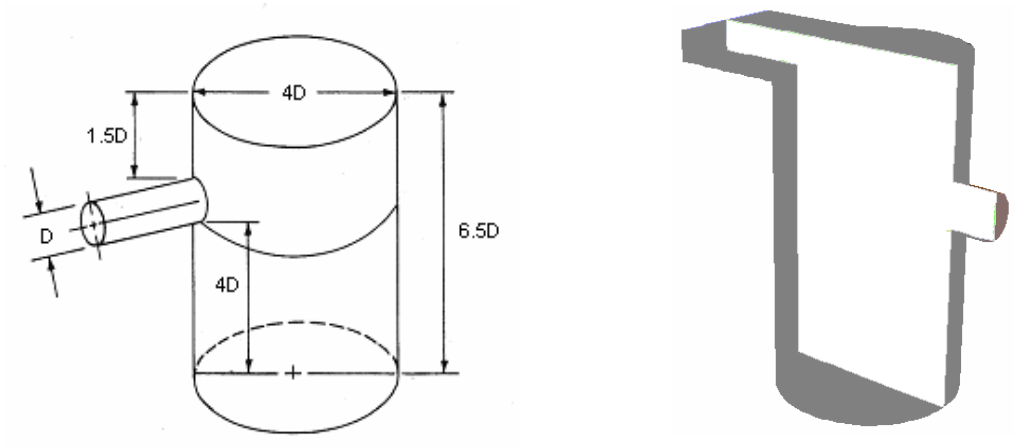

Figure 13.1 Typical catchbasin geometry by Larger, et al. (1977) (left) - 2D longitudinal center-line cross section (right).

\subsubsection{Experimental Design for Four Factors}

A multiphase Eulerian model was implemented for the $2^{4}$-full factorial experimental design, with which it is possible to consider two phases: water, and a dense sediment bed. Because the multiphase Eulerian model is a 
mixture model and does not allow an immiscible water-air interphase, the flow was assumed to be a vertical-submersible water jet. The conditions of the inflow jet were separately determined by CFD modeling of the cascading water from a circular and from a rectangular inlet. Additionally, the sediment particle size was assumed to be constant. Figure 13.2 shows the location of the inlet, outlet, the water depth, and the sediment depth.

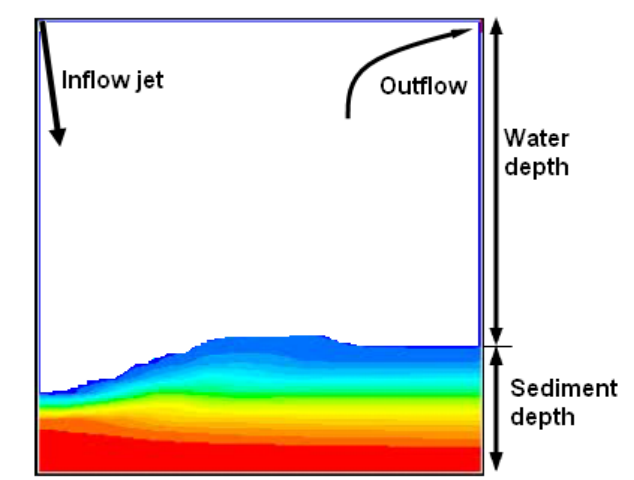

Figure 13.2 Inflow, and outflow directions, water and sediment depth of the $2 \mathrm{D}$ model implemented for the $2^{4}$-full factorial experimental design.

\subsubsection{Evaluation of Shear Stress}

A Volume of Fraction model (VOF) was used to evaluate the shear stress at different sediment elevations. This multiphase model allows immiscible conditions between the water and the air, making it possible to consider the waterfall impact on the water surface in the sump. For this model, two different inlet geometries were evaluated: a $0.8 \mathrm{~m}$-wide rectangular inlet (representing typical gutter flows entering the catchbasin) and a $300-\mathrm{mm}-$ pipe inlet (representing in-line conditions). The water surface into the manholes was set at $1.2 \mathrm{~m}$ above the manhole bottom, which corresponds to the lowest level of the outlet, and the inlet velocity was set as zero. Figure 13.3 shows the three different overlying water depths evaluated and the water surface located at $1.2 \mathrm{~m}$ above the bottom of the catchbasin. 


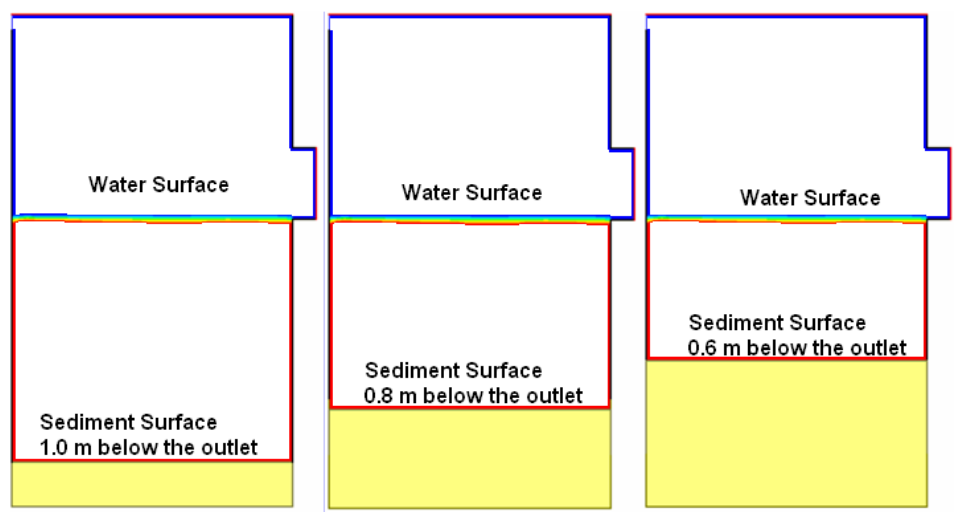

Figure 13.3 Water and sediment depth of the 2D model implemented for the $2^{4}$-full factorial experimental design.

\subsection{Results of the $2^{4}$-Full Factorial Experimental Design}

After simulating all sixteen combinations of treatments for the 3,600 sec durations, the reduction of sediment depth (sediment loss) was plotted as a function of time. The sediment depth is the complement of the water protection depth; if the water depth is $0.2 \mathrm{~m}$, the sediment depth is $1.0 \mathrm{~m}$. Figure 13.4 shows the results obtained from the 2D-CFD model.

Figure 13.4 shows the changes in the sediment depth with time, making it possible to see the effects of the factors and their interactions. As expected, high flows with shallow water depths (AC) result in the fastest washout of the sediment, followed by high flows alone (A). Particle size alone (B) and particle size and specific gravity combined (BD) had little effect on scour.

The significance of the factors and their interactions were examined at six different times: 60, 300, 600, 1,000, 1,800, and 3,000 sec. Each analysis included the determination of the effects of the factors, the normal probability plot of the effects, the ANOVA (with no replicates), and the evaluation of resulting residuals.

The coefficients of the effects for all the evaluated times show that flow rate $(A)$, water depth $(\mathrm{C})$, particle size $(\mathrm{B})$, and the interaction of flow rate and water depth $(\mathrm{AC})$ are the most significant factors in the calculated scour 
(Figure 13.5). In contrast, specific gravity (D) is located at the sixth or eighth position, which indicates that specific gravity is not as relevant as the other main factors and several of the 2-way interaction terms.

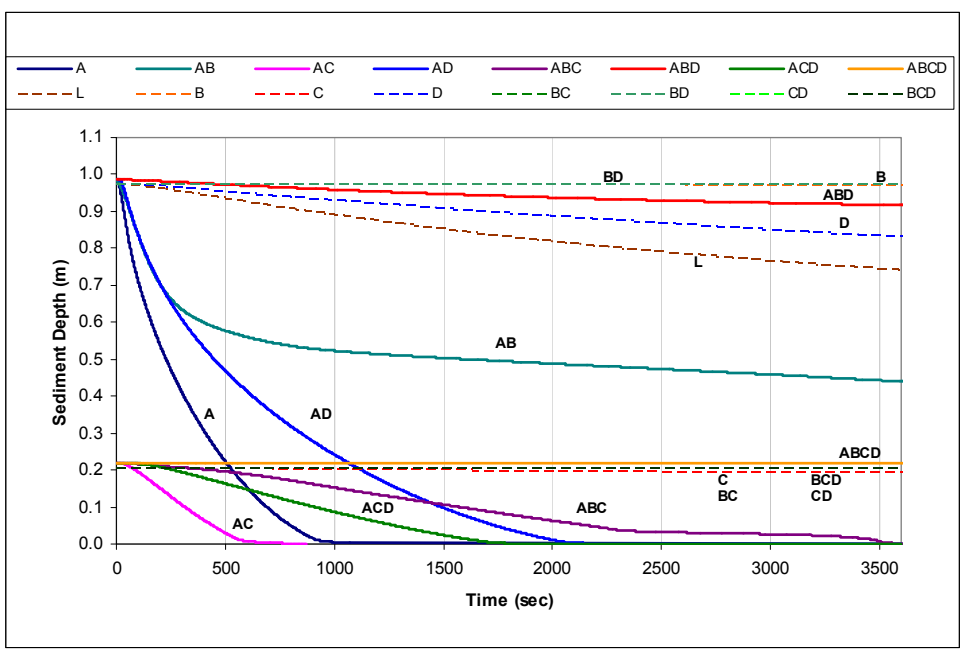

Figure 13.4 Reduction of Sediment Depth as a function of Time for each treatment. Results of the $2^{4}$-full factorial experiment (A: flow rate; $B$ : particle size; C: water depth; and D: specific gravity).

Table 13.3 ANOVA results: p-values for each treatment at different times of the simulation.

\begin{tabular}{crrrrrr}
\hline \multicolumn{7}{c}{ Time $(\mathrm{sec})$} \\
\hline Treatment & \multicolumn{1}{c}{ 60 } & \multicolumn{1}{c}{300} & \multicolumn{1}{c}{600} & \multicolumn{1}{c}{1000} & \multicolumn{1}{c}{1800} & \multicolumn{1}{c}{3000} \\
\hline A & $\mathbf{0 . 0 2}$ & $\mathbf{0 . 0 0 6}$ & $\mathbf{0 . 0 0 3}$ & $\mathbf{0 . 0 0 3}$ & $\mathbf{0 . 0 0 3}$ & $\mathbf{0 . 0 0 3}$ \\
B & 0.14 & 0.06 & $\mathbf{0 . 0 2}$ & $\mathbf{0 . 0 2}$ & $\mathbf{0 . 0 1}$ & $\mathbf{0 . 0 1}$ \\
C & $\mathbf{0 . 0 2}$ & $\mathbf{0 . 0 1}$ & $\mathbf{0 . 0 0 9}$ & $\mathbf{0 . 0 0 9}$ & $\mathbf{0 . 0 1}$ & $\mathbf{0 . 0 0 8}$ \\
D & 0.13 & 0.09 & 0.08 & 0.12 & 0.24 & 0.22 \\
AB & 0.15 & 0.08 & $\mathbf{0 . 0 3}$ & $\mathbf{0 . 0 3}$ & $\mathbf{0 . 0 4}$ & 0.06 \\
AC & $\mathbf{0 . 0 2}$ & $\mathbf{0 . 0 1}$ & $\mathbf{0 . 0 1}$ & $\mathbf{0 . 0 1}$ & $\mathbf{0 . 0 2}$ & $\mathbf{0 . 0 3}$ \\
AD & 0.13 & 0.10 & 0.09 & 0.15 & 0.34 & 0.34 \\
BC & 0.17 & 0.17 & 0.10 & 0.07 & 0.05 & $\mathbf{0 . 0 4}$ \\
BD & 0.82 & 0.86 & 0.97 & 0.77 & 0.41 & 0.34 \\
CD & 0.16 & 0.21 & 0.24 & 0.28 & 0.47 & 0.54 \\
\hline
\end{tabular}



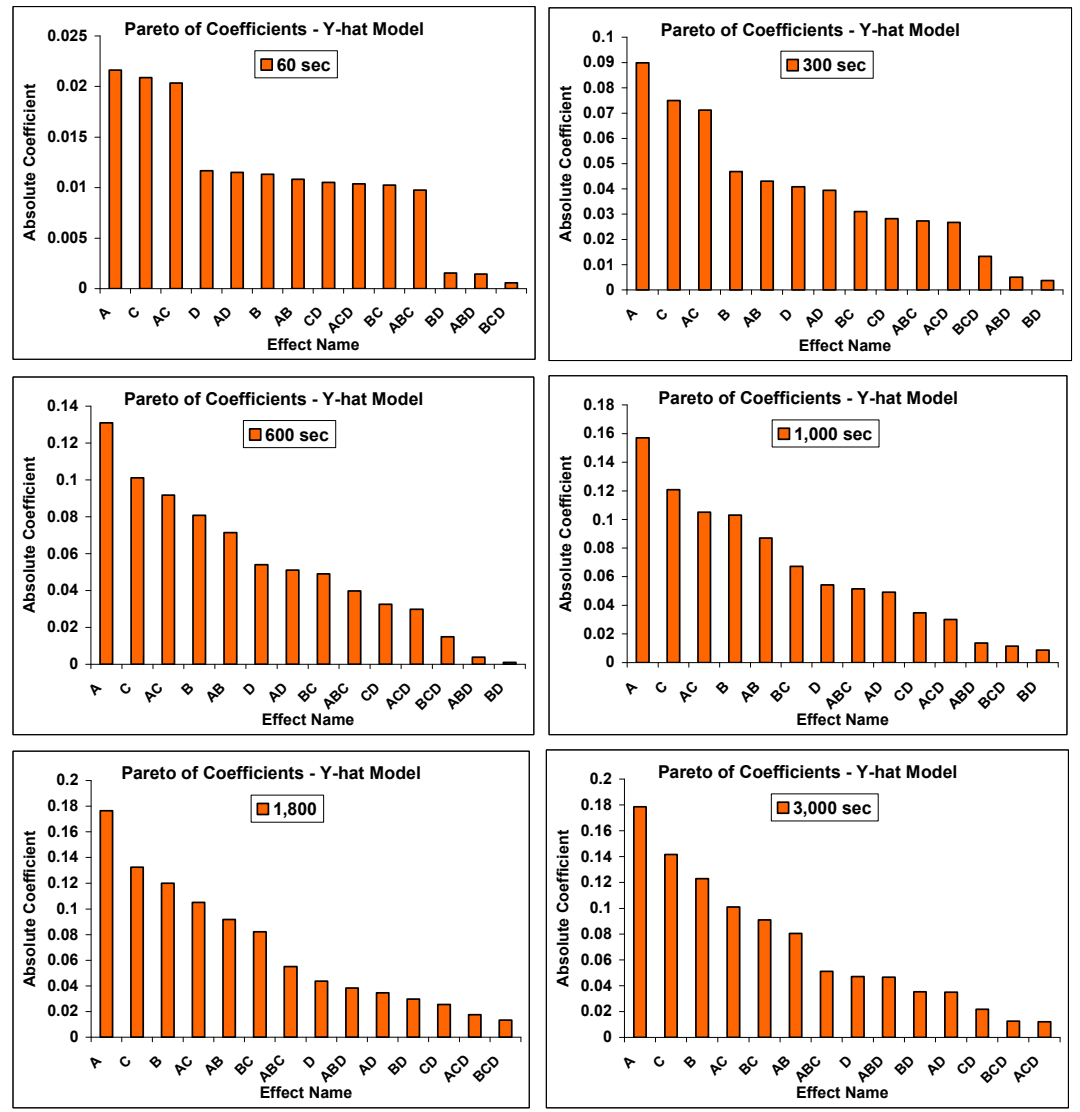

Figure 13.5 Coefficients of effects for each treatment at times $60,300,600$, $1,000,1,800$, and $3,000 \mathrm{sec}$ (A: flow rate; B: particle size; C: water depth; and D: specific gravity).

Similar results were obtained when the factors and interactions were examined using normal probability plots (Figure 13.6); flow rate (A), particle size (B), and water depth (C) were significant, along with flow ratewater depth $(\mathrm{AC})$ interactions for all time steps and flow rate-particle size (AB) interactions for half of the time steps. As noted, specific gravity (D) was not identified as significant, either alone, or in any of the significant interaction terms. To further validate these results using a more quantitative criterion, an ANOVA analysis was used to detect the significant factors and interactions at the $95 \%$, or better, confidence level. 

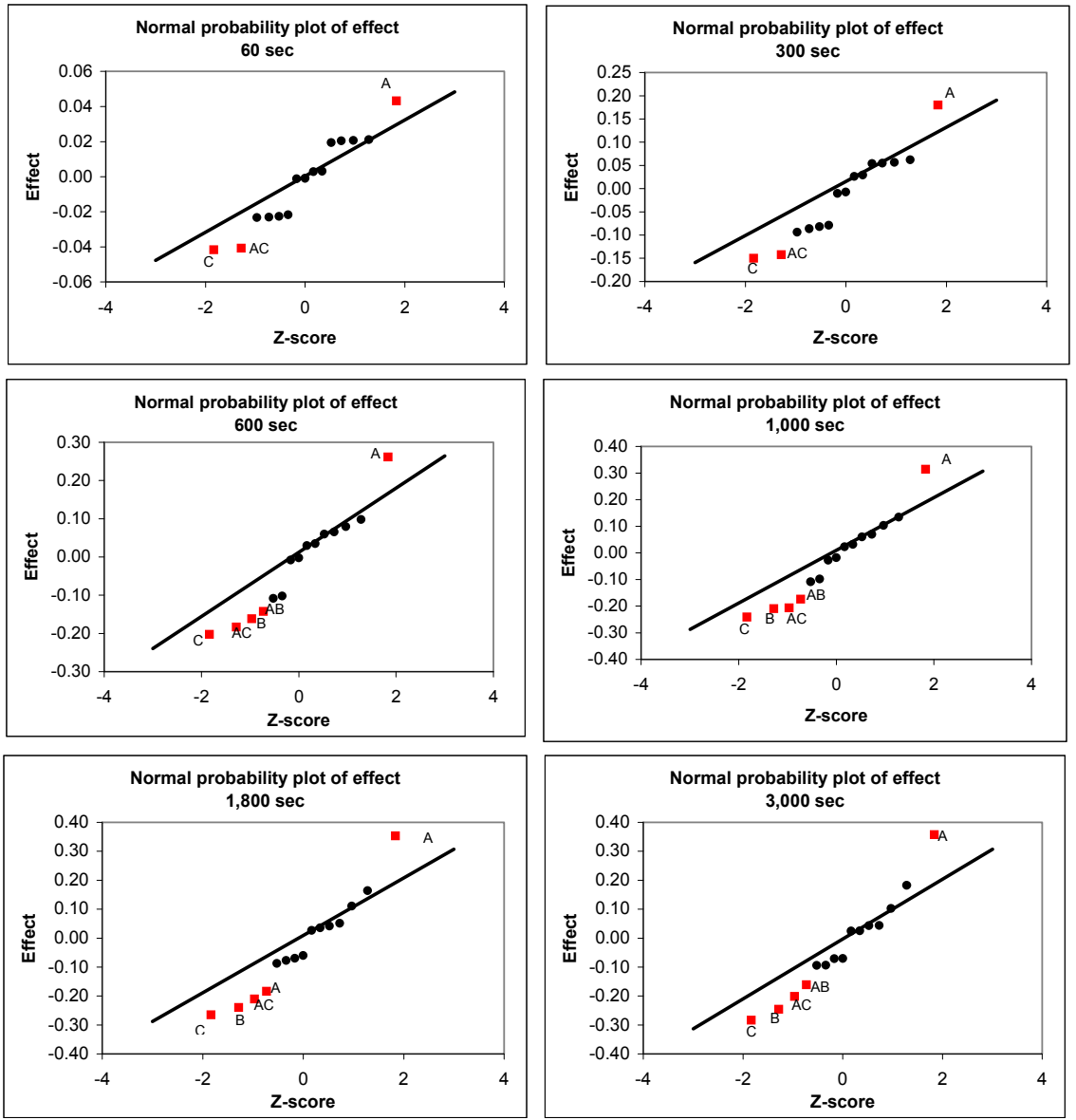

Figure 13.6 Normal probability plot of the effect estimated for times $60,300,600$, $1,000,1,800$, and 3,000 sec (A: flow rate; B: particle size; C: water depth; and D: specific gravity).

An ANOVA with no replicates was used to determine the $p$-values for each factor and interaction (Table 13.3). A confidence level of $95 \%$, or better, would have a p-value of 0.05 , or smaller, and these are indicated with values in bold typefaces. These results are the same as the previous evaluations: showing flow rate, particle size, and water depth as significant factors for times greater that $600 \mathrm{sec}(10 \mathrm{~min}$.). Additionally, the interactions of flow rate-particle size, flow rate-water depth, and particle size-water 
depth were significant. However, specific gravity, or any interaction containing it, was not significant at the $95 \%$ confidence level for any of the evaluated times.
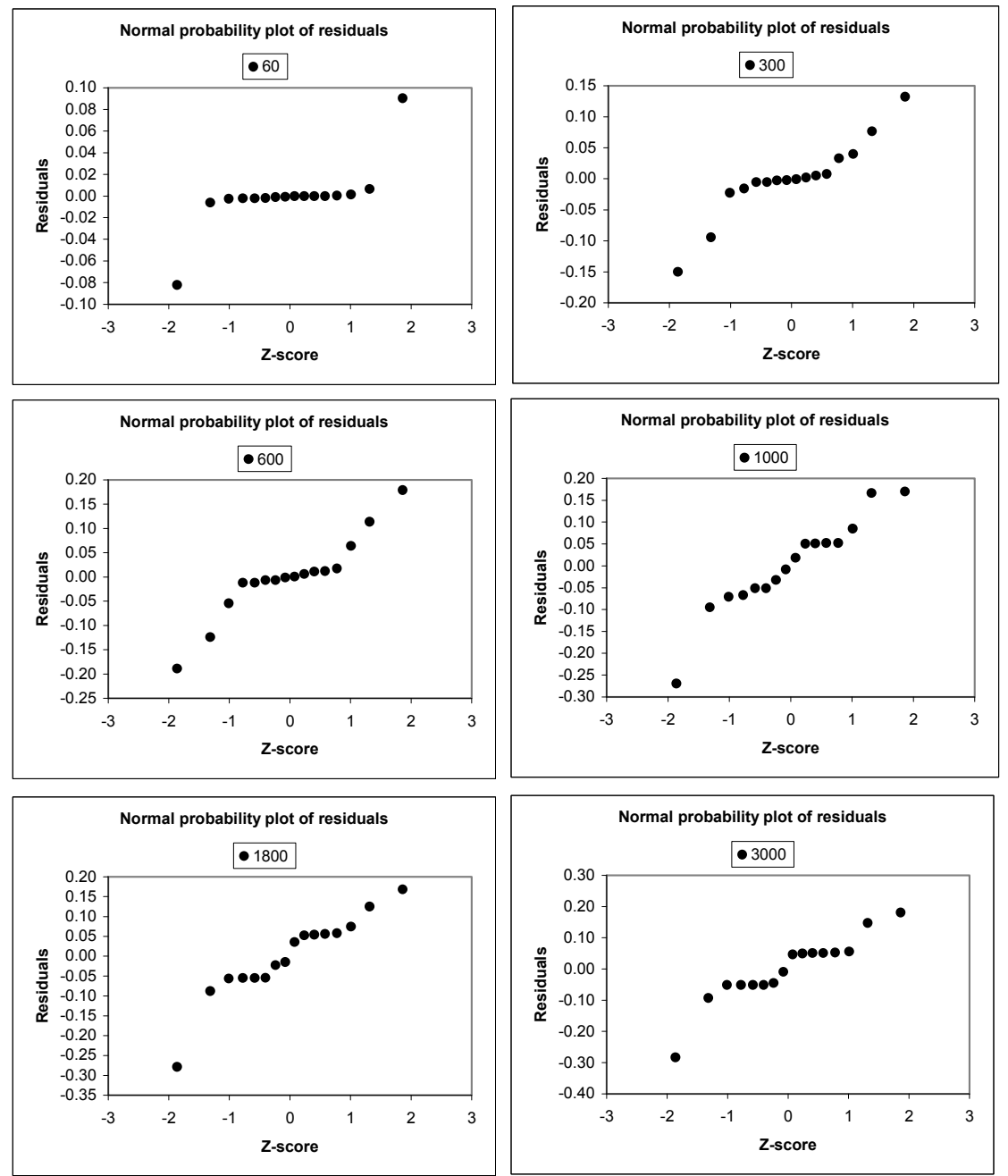

Figure 13.7 Normal probability plot of residuals estimated for times 60,300 , $600,1,000,1,800$, and $3,000 \mathrm{sec}$. 
Additionally, residuals were calculated to determine normality and independency. Figure 13.7 shows that the residuals appear normal for times greater than 1,000 sec (17 min.). However, shorter times show lack of normality. On the other hand, considering that there are only several data points, it is not possible to have a clear impression of homoscedastic or heteroscedastic. However, homoscedastic of the residuals was fair for times greater than $1,000 \mathrm{sec}$.

As expected, flow rate and particle size were identified as significant factors. Moreover, the water depth was also found to be a significant factor that protects the sediment layer from being scoured. However, specific gravity was not as important as the other factors.

\subsection{Results of the Shear Stress Evaluation}

\subsubsection{Comparison of Hydrodynamic Effects Associated with Different Inlets}

Two different inlet geometries were evaluated: a $0.8 \mathrm{~m}$-wide rectangular inlet (representing gutter flows and a $300 \mathrm{~mm}$-diameter pipe inlet representing an in-line installation. Although the inlet flow rate was the same, the hydrodynamic conditions inside the chamber were dramatically different for the two inlet configurations. An initial critical condition occurs when the waterfall impacts the water surface in the chamber. The impact force of the waterfall coming from the pipe inlet is considerably higher than when the inlet is rectangular, even with the same flow and drop height; this is because the impact area is concentrated in a smaller area for the pipe inlet so the momentum transfer per unit width in the chamber is substantially higher compared to the impact of the waterfall from the rectangular inlet which distributes the momentum along its $0.8 \mathrm{~m}$ width.

The difference in the momentum transfer due to the water impact for the two inlet configurations accounts for differences in the depth of the waterfall-induced water jet beneath the water surface. Figure 13.8 shows the differences between the underwater jets generated by the rectangular and the circular inlets; this figure represents a flow rate of $20 \mathrm{~L} / \mathrm{s}$ for both inlet configurations. The bottom of theses figures represents a sediment surface located about $0.8 \mathrm{~m}$ below the outlet elevation. In the case of the rectangular inlet (left) the jet (with velocity magnitudes of about $1.2 \mathrm{~m} / \mathrm{s}$ ) only reaches about $0.15 \mathrm{~m}$ below the outlet; in contrast, the jet reaches about $0.5 \mathrm{~m}$ below 
the outlet when the inlet is circular. These depths define the initial elevations at which the sediment layers may be exposed to potential scour. The other modeled cases showed similar differences in hydrodynamic behavior for the different inlet configurations.

After steady-state hydraulic conditions are established (the volume of water in the chamber is constant with a constant water depth and the inlet flow rate is equal to the outlet flow rate), a rotational velocity field is developed due to the water flowing toward the outlet. This velocity field reaches the sediment surface or the bottom of the chamber. These results are consistent with the results obtained by Faram, et al. (2003) who modeled a similar manhole. The maximum velocity magnitude close to the sediment surface is about $0.2 \mathrm{~m} / \mathrm{s}$ for the rectangular inlet, while it is about $0.35 \mathrm{~m} / \mathrm{s}$ for the circular inlet, both for the $20 \mathrm{~L} / \mathrm{s}$ case. This velocity establishes a shear stress on the sediment.
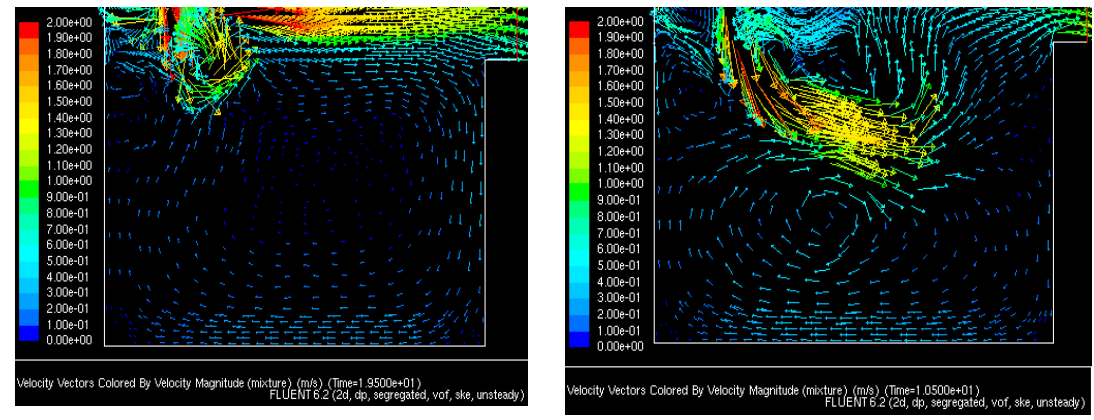

Figure 13.8 Water-fall Impact for different inlet geometries. Flow rate: $20 \mathrm{~L} / \mathrm{s}$, sediment level below the outlet: $0.8 \mathrm{~m}$. Rectangular inlet (left), circular (right).

\subsubsection{Initial Motion and Initial Suspension Criteria}

The critical shear stress defines the limiting condition when the sediment will move or not move from the sediment bed. Typically, the critical shear stress is determined from the Shield's diagram (which assumes a wide flat channel) to determine the initial motion at which bed load will occur. However, in the case of scour in conventional manholes, one has to consider not only the initial motion criterion, but also the initial suspension criterion, and also the unique configuration of the manhole which is being studied. 
Scour in manholes is defined as the migration of sediment out of the catchbasin sump chamber to the catchbasin outlet. This obviously involves the initial motion of the sediment which will cause the sediment bed to shift (typically defined as the bedload in channels and pipes). However, because the surface of the sediment layer deposited in the manhole is located below the outlet elevation, sediment bed shifting alone will not necessarily represent migration out of the device because the sediment does not necessarily reach the elevated outlet. Therefore, only suspended sediment will be assumed to leave the chamber.

Different shear stress criteria were reviewed for this chapter in order to have a better understanding of the initial motion and initial suspension shear stress thresholds as a function of sediment characteristics. Shields, White and Iwagaki (Garden and Raju 1977) studied the critical shear stress for initial motion. Their results showed that the dimensionless shear stress $\left(\tau^{*}\right)$ has the same trend for diameters between $0.1 \mathrm{~mm}$ to $10 \mathrm{~mm}$. Their analyses are also consistent with experimental values obtained by other researchers, such as Kramer, Indri, and Chang, among others (Garden and Raju 1977). These criteria give a better approach about the critical shear stress for initial motion, considering that they are based on theoretical and semi-theoretical analysis, and have also been widely used, specially the Shields diagram.

The Cheng-Chiew criterion (Cheng and Chiew 1999), which involves both initial motion and initial suspension, was also evaluated. This criterion relates the critical shear stress with the probability that sediment with a particular specific gravity, diameter, and settling velocity, becomes bed load or gets suspended. According to Cheng and Chiew (1999) the initial motion threshold is determined when the probability of suspension is close to zero $\left(1 \times 10^{-7}\right)$, and the initial suspension threshold is determined when the probability is about $1 \%$. Obviously, there is not a specific line that determines when the sediment will be suspended, but a range is usually used; however, according to Cheng and Chiew (1999), this value may be adopted for determining the initial suspension. Figure 13.9 shows the dimensionless shear stress $\left(\tau^{*}\right)$ as a function of the Reynolds number of the particle ( $\left.\mathrm{Re}^{*}\right)$ calculated with the Cheng-Chiew criterion. Shields (initial motion), Van Rijn and Xie criteria (initial suspension), are also shown.

Figure 13.9 clearly shows that the dimensionless-critical shear stress calculated by using the Cheng-Chiew criterion is less than when calculated using the Shields method for Reynolds numbers of the particle less than 30 . Therefore, the selection of the Cheng-Chiew criterion likely results in a conservative value for initial motion shear stress. Moreover, the ChengChiew criterion involves the criteria of Xie and Van Rijn for the initial 
suspension threshold. Therefore, the Cheng-Chiew criterion was selected to determine the critical shear stress for initial motion and initial suspension thresholds, using a specific gravity of 2.5 .

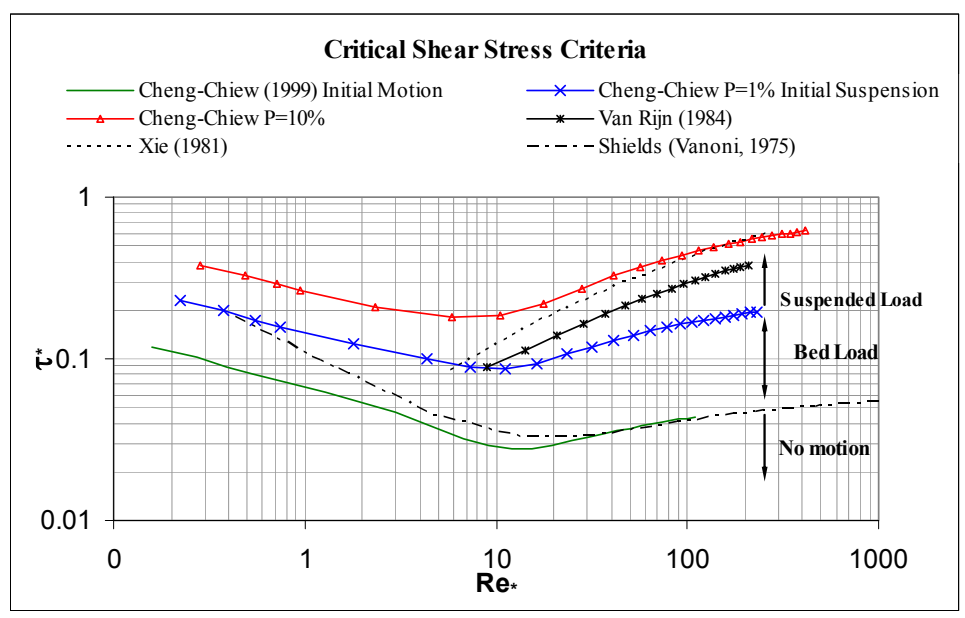

Figure 13.9 Critical shear stress criteria.

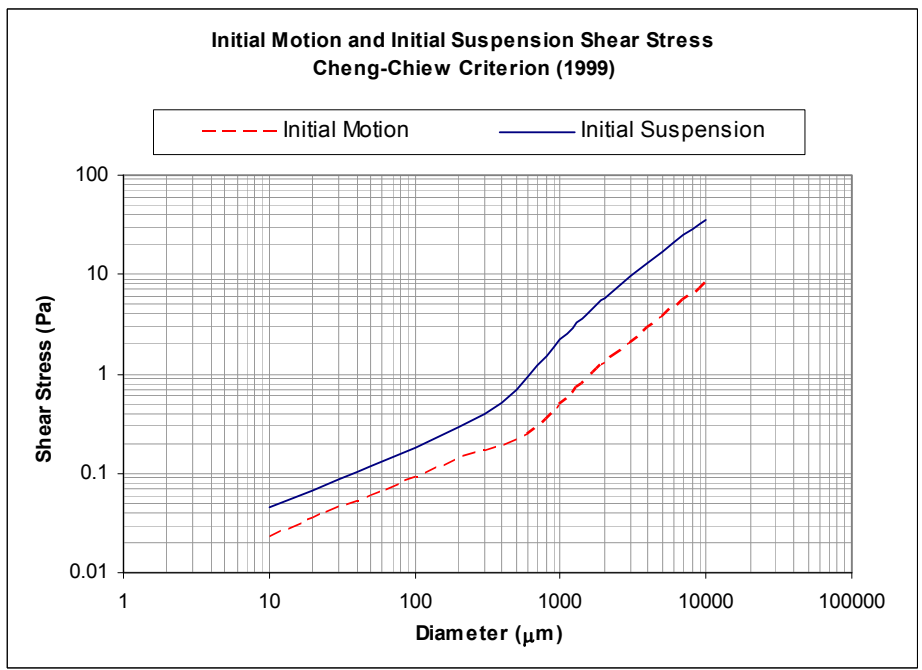

Figure 13.10 Initial motion and initial suspension shear stress as a function of particle size with specific gravity 2.5 - Cheng-Chiew Criterion. 
Figure 13.10 shows the critical shear stress based on the Cheng-Chiew criterion as a function of sediment size (diameter) with specific gravity 2.5 .

\subsubsection{Shear Stress Analysis}

Initial motion is the threshold at which the bed load is assumed to begin to move. However, bed load would not necessarily represent migration of sediment out of the catchbasin sump because the sediment surface is located below the outlet elevation; sediment will move up and down close to the bed without reaching a suspended condition. On the other hand, initial suspension is the threshold at which the sediment will become suspended. Once the sediment becomes suspended, it is much more likely to be flushed out of the sump. When this condition occurs, the mass of sediment in the catchbasin sump will decrease with time. Therefore, scour will be defined as the reduction of height of the sediment layer.

After simulating 30 different cases, combining flow rate, sediment layer elevation, and inlet geometry, a series of graphs were developed and compared to the initial suspended threshold for a range of particle size up to $2,000 \mu \mathrm{m}$.

Rectangular Inlet of 0.8-m wide: When the flow rate is $40 \mathrm{~L} / \mathrm{s}$, particle sizes smaller than about $2,000 \mu \mathrm{m}$ are exposed to initial motion as well as to initial suspension at $0.6 \mathrm{~m}$ below the outlet, particle sizes smaller than 500 $\mu \mathrm{m}$ are exposed to initial suspension at 0.8 and $1.0 \mathrm{~m}$. After about $10 \mathrm{sec}$, there is no substantial difference among the shear stress magnitudes at different levels, which are between 0.5 and $1.0 \mathrm{~Pa}$. This indicates that the velocity field generated by a flow rate of $40 \mathrm{~L} / \mathrm{s}$ affects the whole water volume in the chamber. At 20,10,5, and $2 \mathrm{~L} / \mathrm{s}$ flows, even though the water surface is impacted at about $0.4 \mathrm{sec}$, the shear stress begins to be important only after some time when the velocity field starts developing. The increasing rate of the shear stress is initially manifested at $0.6 \mathrm{~m}$ below the outlet, then at $0.8 \mathrm{~m}$, and then at $1.0 \mathrm{~m}$, which is consistent with the development of the velocity field. However, once the shear stress stabilizes, there is no substantial difference of shear stress magnitudes at different elevations. Particle sizes smaller than $500 \mu \mathrm{m}, 300 \mu \mathrm{m}, 50 \mu \mathrm{m}$, and $40 \mu \mathrm{m}$ would be exposed to initial suspension at $20 \mathrm{~L} / \mathrm{s}, 10 \mathrm{~L} / \mathrm{s}, 5 \mathrm{~L} / \mathrm{s}$, and $2 \mathrm{~L} / \mathrm{s}$ flows respectively at 0.6 , and $0.8 \mathrm{~m}$ below the outlet. At $1.0 \mathrm{~m}$ below the outlet, the shear stress is reduced for 10,5 , and $2 \mathrm{~L} / \mathrm{s}$ flows, at which particle sizes smaller than $100 \mu \mathrm{m}, 30 \mu \mathrm{m}$, and $20 \mu \mathrm{m}$, respectively, are exposed to initial suspension. Figure 13.11 shows these results. 

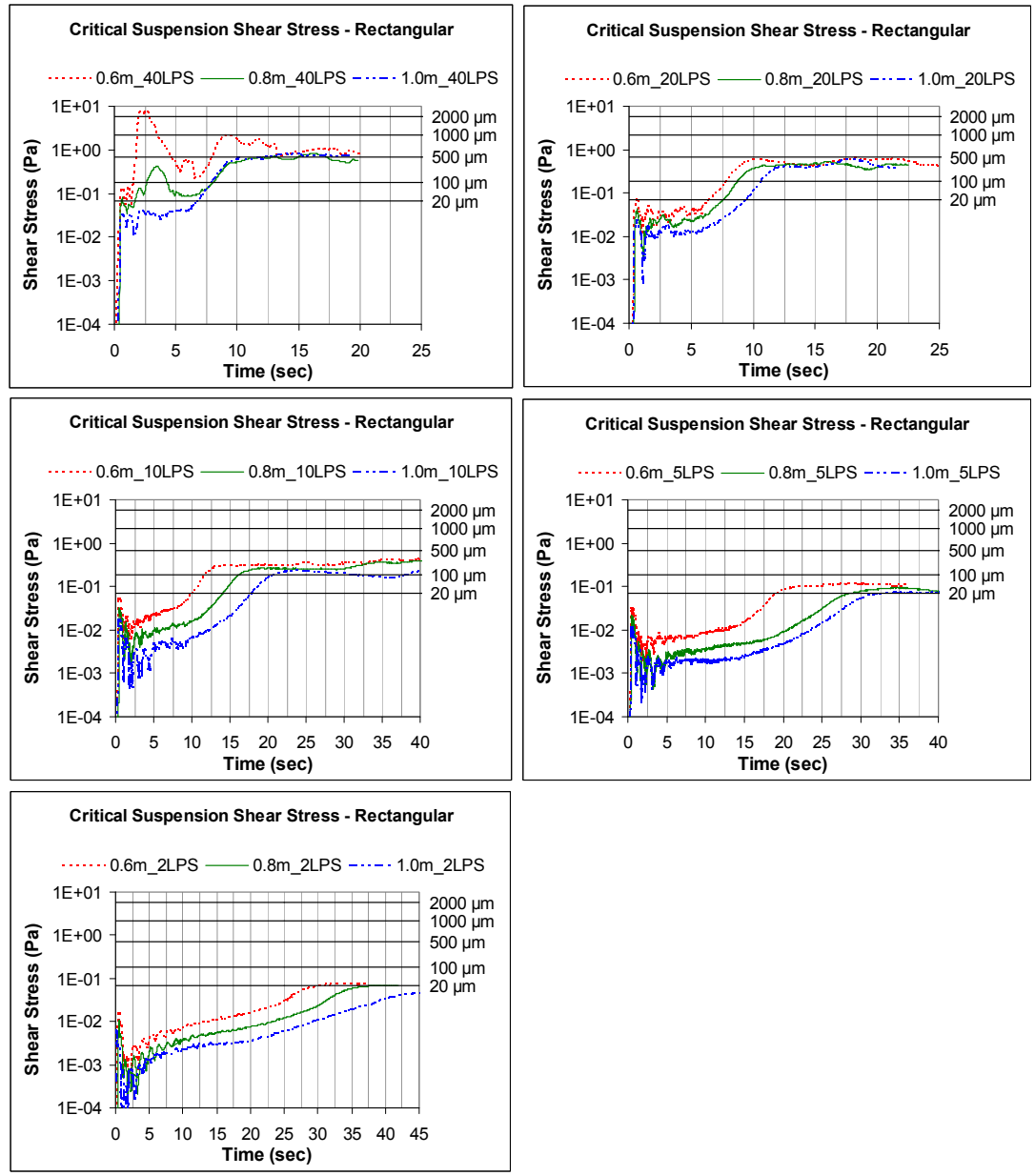

Figure 13.11 Shear stress on the sediment layer at different elevations in a catchbasin sump with a rectangular inlet $0.8-\mathrm{m}$ wide, and initial suspension threshold for different particle sizes. Series of graphs classified by flow rates: 40, 20, 10, 5, and 2 LPS.

Circular inlet of 300-mm diameter: When the inlet is a 300-mm diameter pipe, the shear stress magnitudes and turbulence conditions are considerably higher than when the inlet flow is from a rectangular gutter channel. For 40 and $20 \mathrm{~L} / \mathrm{s}$ flows, shear stress magnitudes of about $20 \mathrm{~Pa}$ exceed the critical 
value for 2,000 $\mu \mathrm{m}$ particles for initial suspension at any elevation of the sediment surface; this shear stress is mainly caused by the impact of the water jet.
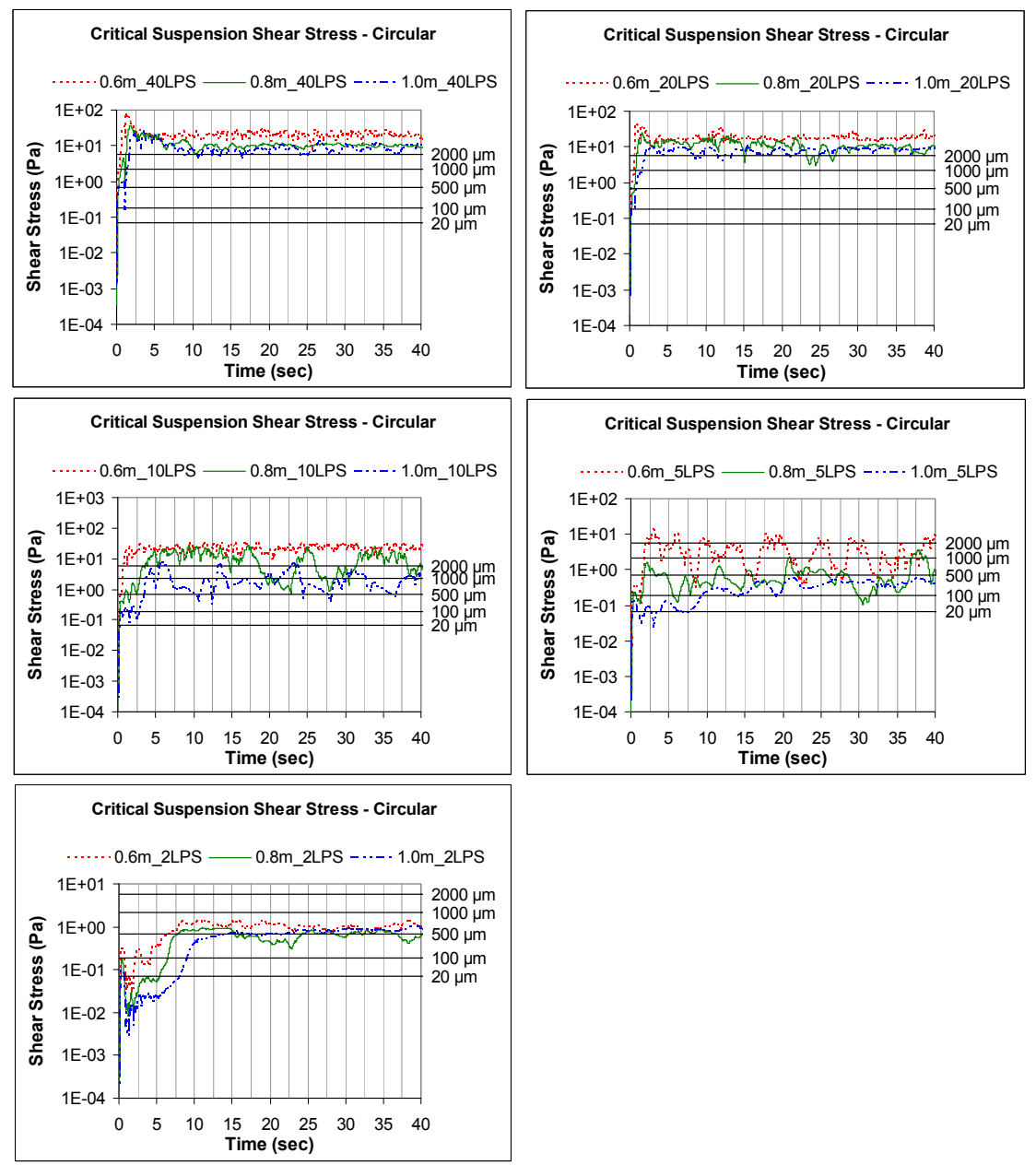

Figure 13.12 Shear stress on the sediment layer at different elevations in a catchbasin sump with a circular inlet $300-\mathrm{mm}$ in diameter, and initial suspension threshold for different particle sizes. Series of graphs classified by flow rates: $40,20,10,5$, and 2 LPS. 
However, when the flow rate is $10 \mathrm{~L} / \mathrm{s}$, the protecting water layer above the sediment surface becomes important and the shear stress is reduced to about $4.0 \mathrm{~Pa}$ at $0.8 \mathrm{~m}$ below the outlet. At $5 \mathrm{~L} / \mathrm{s}$ flows, the water jet still generates shear stress values above $6.0 \mathrm{~Pa}$ at $0.6 \mathrm{~m}$ below the outlet, when particles smaller than $2,000 \mu \mathrm{m}$ are expected to become suspended. However, at $0.8 \mathrm{~m}$ below the outlet, the shear stress starts being more stable at about $1.0 \mathrm{~Pa}$, when particles smaller than about $600 \mu \mathrm{m}$ may become suspended for any of the three evaluated elevations. Figure 13.12 shows these results.

It is evident that the inlet geometry considerably affects the potential scour of sediment in a catchbasin sump. In-line catchbasin sumps with an inlet pipe without any energy dissipating device will certainly cause more resuspension of previously deposited sediment than a typical gutter having a wide rectangular inlet.

On the other hand, considering that low flow rates associated with typical rainfall events occur more often than high flow rates (Table 13.2, Pitt and Khambhammettu 2006), the expected sediment removal performance in the sump may be high because the hydrodynamic conditions are appropriate for particle settling. A dynamic equilibrium of scour-sedimentation of sediment may be reached in the sump, maintaining a constant sediment mass in the chamber at a specific sediment depth (as noted during prior field studies). However, if no scour protection is implemented in the catchbasin sump, a portion of the previously captured sediment may be scoured in only few minutes if an unusually high flow rate occurs, although that has not been seen during the field activities, even with unusual flows and deep sediments (Pitt 1979 and 1985).

\subsection{Conclusions}

Flow rate, particle size, water depth, and their interactions, are significant factors that affect the scour of sediment in a conventional catchbasin sump. Specific gravity is not as important as these other factors over time under continuous flow conditions in term of loss of sediment mass out of a conventional catchbasin sump.

The inlet geometry has a significant effect on the scour potential of sediments captured in conventional catchbasin sumps. The impact force will be greater when the waterfall is concentrated in the smaller area associated with a pipe inlet. However, when the flow rates are very high, the shear 
stresses generated by both inlet geometries exceed the suspending-critical shear stress of particles $2,000 \mu \mathrm{m}$ in diameter and smaller.

The overlying water layer depth above the sediment has an important function in protecting the sediment layer from scour. High shear stresses caused by the impacting water jet will not easily reach the sediment surface if the water is deep. However, once the flow is stabilized, the developed velocity field will reach the sediment surface at all depths, so the important shear stress may be best representative in this condition. Moreover, with deeper water, the resulting shear stress conditions on the sediment surface are less than for shallower water, for all modeled conditions.

Armoring effects, the consolidation of the deposited sediment bed, and cohesive properties of clay, were not included in these analyses. These are relevant factors that suggest a greater permissible shear stress of the sediment bed before scour, and therefore require further analysis. Recent results, obtained from a full-scale physical model, have shown that the armoring effect protects the sediment layer after equilibrium between flow and particle sizes on the armoring surface is reached.

The results show that flows smaller than $2.0 \mathrm{~L} / \mathrm{s}$ (32 GPM), typical for stormwater catchbasins, do not expose particles greater than $50 \mu \mathrm{m}$ to suspension in manholes with rectangular inlets wider than $0.8 \mathrm{~m}(2.6 \mathrm{ft}$.). This suggests that the sediment would not be exposed to scour most of the time, considering that higher flow rates are less frequent. This has been confirmed during field studies of catchbasin sumps when the typically smallest particle sizes found are about $50 \mu \mathrm{m}$.

\section{References}

Box, G.E.P., W.G. Hunter, and J.S. Hunter (1978). Statistics for Experimenters. John Wiley and Sons. New York.

Cheng N., Chiew Y., (1999) "Analysis of Initiation of Sediment Suspension from Bed Load," Journal of Hydraulic Eng. Vol 125, No. 8, pp 855-861, August, 1999.

Faram, M.; Harwood, R.; Deahl, P., "Investigation into the Sediment Removal and Retention Capabilities of Stormwater Treatment Chambers," StormCon Conference, Texas, USA, July 2003

FLUENT 6.2. Computational Fluid Dynamic (CFD) Software. User's Manual. http://www.fluent.com/

Garde, R., Ranga Raju K., (1977) Mechanics of Sediment Transportation and Alluvial Stream Problems, Edition John Wiley \& Sons, New Delhi, pp 45-68.

Lager, J.A., W.G. Smith, W.G. Lynard, R.M. Finn, and E.J. Finnemore. (1977), "Urban Stormwater Management and Technology: Update and Users' Guide. U.S. EPA-600/877-014", Cincinnati, Ohio, September 1977. 
Pitt, R. (1979) Demonstration of Nonpoint Pollution Abatement Through Improved Street Cleaning Practices, EPA-600/2-79-161, U.S. Environmental Protection Agency, Cincinnati, Ohio. 270 pgs.

Pitt, R. (1985),“Characterizing and Controlling Urban Runoff through Street and Sewerage Cleaning,’U.S.EPA/2-85/038. PB 85-186500/AS. Cincinnati, June 1985

Pitt, R. and U. Khambhammettu. (2006), "Field Verification Tests of the UpFlowTM Filter. Small Business Innovative Research, Phase 2 (SBIR2)" U.S. EPA, Edison, NJ. 275 pages. March 2006.

U.S. Environmental Protection Agency (1977), "Catchbasin Technology Overview and Assessment,” EPA-600/2-77-051. Authors: Larger J., Smith W., Tchobanoglous G., Metcalf \& Eddy, Inc. OHIO, 1977. 
